\title{
How Well Do the Rosgen Classification and Associated "Natural Channel Design” Methods Integrate and Quantify Fluvial Processes and Channel Response?
}

\author{
A. Simon ${ }^{1}$, M.Doyle ${ }^{2}$ M. Kondolf ${ }^{3}$, F.D. Shields Jr. ${ }^{1}$, B. Rhoads ${ }^{4}$, G. Grant ${ }^{5}$, \\ F. Fitzpatrick ${ }^{6}$, K. Juracek ${ }^{7}$, M. McPhillips ${ }^{8}$ and J. MacBroom ${ }^{9}$ \\ ${ }^{1}$ USDA-ARS, National Sedimentation Laboratory, Oxford, MS \\ ${ }^{2}$ Department of Geography, University of North Carolina, Chapel Hill, NC \\ ${ }^{3}$ Department of Landscape Architecture and Environmental Planning, Universityof \\ California at Berkeley, Berkeley, CA \\ ${ }^{4}$ Department of Geography, University of Illinois, Urbana-Champaign, IL \\ ${ }^{5}$ U.S. Forest Service, Corvallis, OR \\ ${ }^{6}$ U.S. Geological Survey, Middleton, WI \\ ${ }^{7}$ U.S. Geological Survey, Lawrence, KS \\ ${ }^{8}$ Intuition and Logic Inc., Amelia Island, FL \\ ${ }^{9}$ Milone and MacBroom Inc. and Yale University, New Haven, CT
}

\section{Introduction}

Over the past 10 years the Rosgen classification system (Rosgen, 1994) and its associated methods of "natural channel design" (Rosgen, 1996) have become synonymous (to many without prior knowledge of the field) with the term "stream restoration" and the science of fluvial geomorphology. Since the mid 1990s, this classification approach has become widely, and perhaps dominantly adopted by governmental agencies, particularly those funding restoration projects (Malakoff, 2004). For example, in a request for proposals for the restoration of Trout Creek in Montana, the Natural Resources Conservation Service required "experience in the use and application of a stream classification system and its implementation" (MFWP, 1998). Similarly, classification systems have been used in evaluation guides for riparian areas and U.S. Forest Service management plans. Most notably, many highly trained geomorphologists and hydraulic engineers are often held suspect, or even thought incorrect, if their approach does not include reference to or application of a classification system (Malakoff, 2004). This, combined with the paraprofessional training provided by some involved in "natural channel design" empower individuals and groups with limited backgrounds in stream and watershed sciences to engineer wholesale re-patterning of stream reaches using 50-year old technology that was never intended for engineering design.

At Level I, the Rosgen classification system consists of eight or nine major stream types, based on hydraulic-geometry relations and four other measures of channel shape to distinguish the dimensions of alluvial stream channels as a function of the bankfull stage. Six classes of the particle size of the boundary sediments 
are used to further sub-divide each of the major stream types, resulting in 48 or 54 stream types. Aside from the difficulty in identifying bankfull stage, particularly in incising channels, and the issue of sampling from two distinct populations (beds and banks) to classify the boundary sediments, the classification provides a consistent and reproducible means for practitioners to describe channel morphology although difficulties have been encountered in lower-gradient stream systems. Use of the scheme to communicate between users or as a conceptual model, however, has not justified its use for engineering design or for predicting river behavior; its use for designing mitigation projects, therefore, seems beyond its technical scope.

\section{Fundamental Issues with Applying the Rosgen Classification}

Application of the Rosgen methodology associated with classification can lead to inconsistencies in classification. Problems can be encountered with:

1. definition of the bankfull level (Williams, 1978; Juracek and Fitzpatrick, 2003), and

2. classification of the dominant type of channel materials (Kuhnle and Simon, 2000).

The simple definition of "bankfull" by Leopold et al. (1964), as the "flow that just spills out onto the floodplain" has produced confusion (Williams, 1978). One of the primary reasons for the confusion in identifying bankfull stage is that as originally defined bankfull discharge and the dimensions represented by hydraulic geometry relations refer to stable channels. This is a critical issue in that "natural channel design" aims to restore "un-natural" and disturbed channels. A bankfull level in unstable streams can be exceedingly difficult to identify particularly in erosional channels because of a lack of depositional features and because channel dimensions, including water-surface elevations (of specific discharges), are changing with time.

Rosgen stipulates that to characterize the boundary sediments for classification purposes, particle counts should be conducted from the bankfull level, down the bank across the channel bed and up the opposite bank to the bankfull level (Rosgen, 1996; p. 5-25). This idea may date to work by Schumm (1960) in his report describing the shape of alluvial channels (mostly Midwestern) in relation to the percentage of silt and clay in the channel boundary. This approach, however, represents the mixing of two distinct populations of alluvial materials, potentially laid down at different times, under different conditions, and requiring different forces and processes to mobilize. Such a particle-size distribution, like a mixture of apples and oranges, is of questionable utility in geomorphic analysis (Kondolf et al. 2003) and not useful for analysis of hydraulic erosion of bed or bank material. In fact, it is the authors' experience that numerous extensive particle-size data sets collected by state and federal agencies cannot be used for analysis of entrainment and sediment transport because of this problem in sampling technique.

Related to this problem of sampling mixed populations is the issue of the potential for inconsistent classification. For example, two " $C$ " channels one with gravel bed and silt-clay banks, the other with sand bed and sand banks might both have median 
diameters in the sand range, resulting in classification as stream type C5. Clearly these two channels would have completely different sediment-transport regimes. Similarly, C channels having bedrock banks will, once disturbed, behave very differently than those having bedrock outcrops on the bed yet both would be classified as C1. Finally, some of the confusion may be related to the different definitions of the type of boundary materials needed for classification at Level II. Rosgen (1996) indicates that bed material be used as a "delineative criteria" (Figure 5-2, p. 5-5) but channel material in the "classification key" (Figure 5-3, p. 5-6) and discussion of sampling methods (p.5-25).

\section{Channel Form: Use and Misuse}

Channel form has long been recognized as a diagnostic tool in evaluating fluvial landforms. Since Davis (1909) conceptualized the temporal aspect of channel and drainage basin evolution in the "cycle of erosion," geographers, geologists, and geomorphologists have used channel form as a parameter in classification, analysis, and prediction of fluvial response. Davis' view of fluvial landscapes was simplistic and contrasted with the detailed measurements of sediment-transport processes by Gilbert (1914). These works represent complimentary extremes that have influenced subsequent approaches to the study of alluvial streams. Davis' work represents largescale, qualitative assessments of channel form by which inferences about smallerscale processes were advanced. Conversely, Gilbert's work represents the use of quantitative measurements by which inferences about larger-scale processes were advanced. Links between channel form and process have been the foundation of our understanding of fluvial geomorphology and as such, have been the topic of many textbooks and reports (e.g. Leopold et al. 1964; Morisawa 1968; Gregory and Walling 1973; Schumm 1977; Richards 1982; Simon, 1994; Knighton 1998).

Though Gilbert and Davis were both respected geomorphologists, it was Davis' historic view of geomorphology that dominated geomorphic investigation for the first half of the twentieth century. Sack (1992) offers three possible reasons for why Davisian geomorphology became widely accepted during this time:

1. the application of a life-cycle analogy from biology to other fields was fashionable at the time;

2. the non-quantitative nature of the geographical cycle made it understandable to a large sector of the population; and

3. Davis, being a professor at Harvard, taught his model to numerous students, many of whom subsequently taught their students.

Rosgens's assumption that one can predict the future behavior of a landscape from its appearance is strikingly reminiscent of Davis' cycle of erosion. The rationale for the popularity of the Davisian approach also sounds remarkably similar to the current popularity of the Rosgen approach. However, Davis' ideas about landscape evolution have largely been made obsolete by progress in earth science over the last century that has revealed a much more complex system. Gilbert's findings, and more specifically his data, are still in use today. There are, however, crucial differences between Davis' view of geomorphology in the early $20^{\text {th }}$ century and the 
classification approach to river restoration today. First, while Davis' approach was scientifically accepted as a valid approach to geomorphology for almost fifty years, the classification approach to restoration design has been criticized since its first introduction to the scientific community, and remains without support in much of the peer-reviewed scientific literature (Kondolf, 1995; Miller and Ritter, 1996; Doyle and Harbor, 2000; Kuhnle and Simon, 2000; Juracek and Fitzpatrick, 2003).

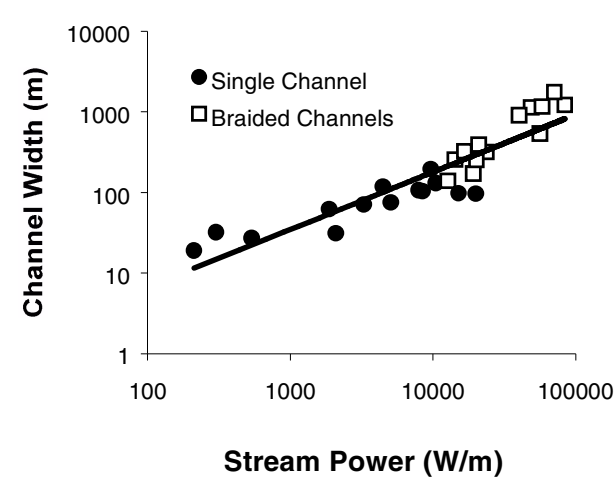

Figure 1. Continuum of channel width with stream power.

Form-based classification schemes are valuable communication and education tools (Miller and Ritter, 1996). However, it is not entirely clear that classification systems are needed, or are not misleading, as typical geomorphic analysis is sufficient to provide necessary information for quantifying geomorphic processes (Ashmore, 1999). For example, data from braided and singlechannel rivers in New Zealand (Church and Rood, 1983) would fall into Rosgen class D and C channels, respectively (Figure 1). When analyzing channel width as a function of discharge, a classification approach suggests that the variation in width is the result of a change in stream type. Classification approaches may even suggest that the D type channel "should" be "restored" to a C type channel. However, if the data are treated continuously using stream power as a metric, the width discrepancy can be seen as the combined effect of slope and discharge.

Channel form, which includes measurements and descriptions of the shape of channel profiles, cross-sections, and planforms, can be used in combination with other attributes of a stream system, such as riparian vegetation and character of the boundary sediments, to infer dominant trends in channel processes and response (Simon and Hupp 1986; Montgomery and Buffington 1997; Elliott et al. 1999). However, using channel form to quantitatively predict channel adjustments, system disturbances or rates of sediment transport, without rigorous analysis of channel processes is flawed (Miller and Ritter 1996). The ramifications of this can be dramatic as shown in Figure 2, a project using "natural channel design" of a C4 stream type on the Uvas Creek, California (Kondolf et al. 2001). Another example of how the "natural channel design" approach would be untenable is shown in Figure 3.

The key to using channel form in the analysis of fluvial landforms must be based on either (1) measurements of parameters that aid in quantifying channel processes such as flow hydraulics, sediment transport, and bank stability or, (2) observations of diagnostic characteristics that provide information on active channel processes. Measurements should either directly or indirectly lead to analysis of those forces acting on the channel boundary and those forces resisting entrainment. 

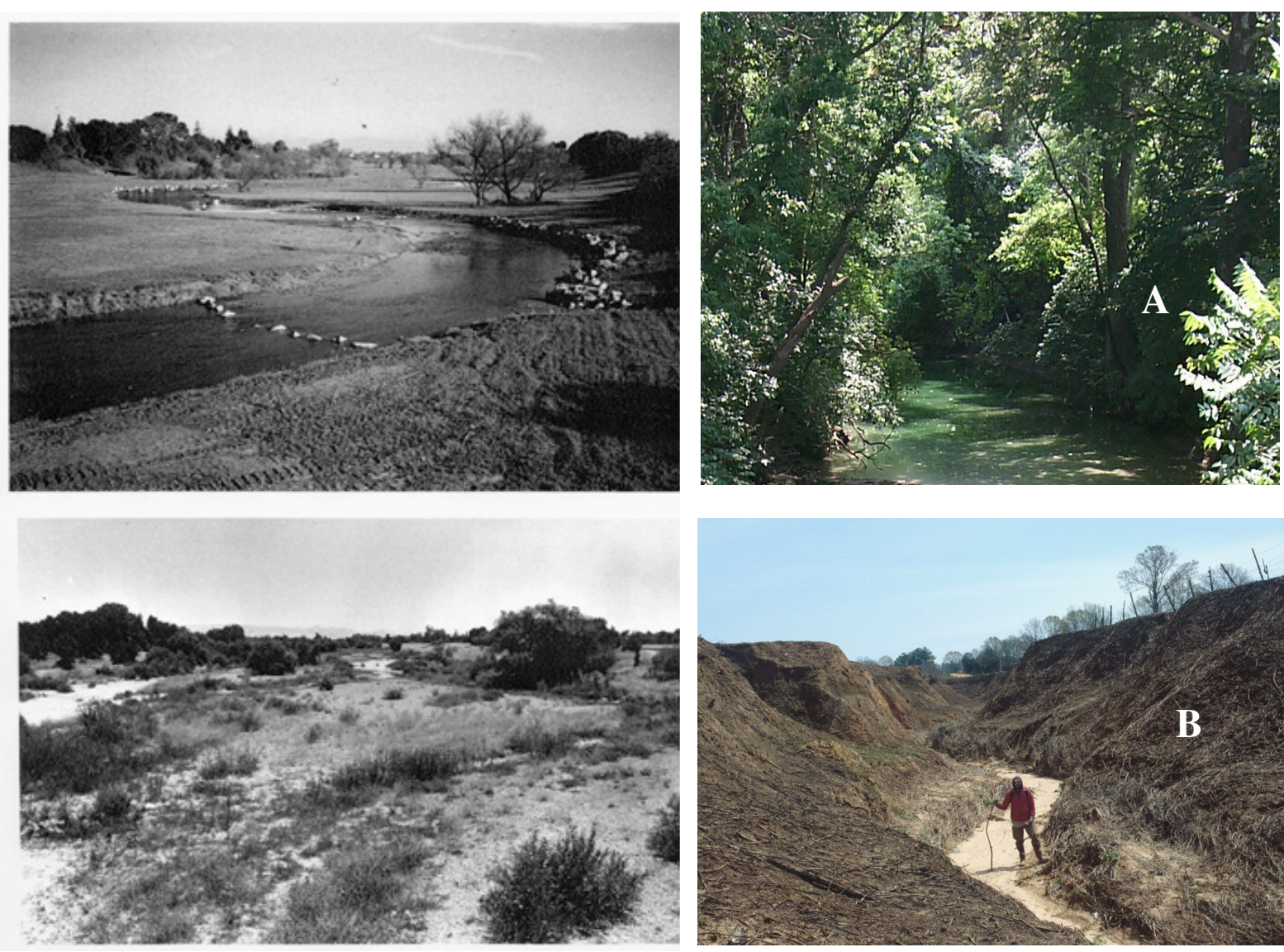

Figure 2. "Natural channel design" of Uvas Creek, California (A), and following a 6-year flood (B). From Kondolf et al., 2001, used with permission of Elsevier Publishers.

Figure 3. "Reference reach" as would be defined by "natural channel design" approach (A), and unstable reach (B) on Goodwin Creek, Mississippi. Sites are about $100 \mathrm{~m}$ apart, separated by a supercritical flume. How would a practitioner using "natural channel design" address this situation for a potential mitigation project?

\section{An Alternative Classification Approach Based on Process}

As an alternative to form-based classification, there are several process-based classifications available that allow assessing likely future geomorphic conditions based on current forms, although these are based on specific geomorphic processes and in some cases, conditions for particular regions (e.g., Simon and Hupp, 1986; Simon, 1989; Montgomery and Buffington, 1997; Elliott, et al., 1999).

Understanding alluvial channel behavior, channel response to disturbances and stable channel forms can be accomplished by concentrating on those factors that directly control the balance or imbalance between applied forces and boundary resistance. This means correctly identifying active processes. If force and resistance are 
generally in balance over a period of years, a channel reach will experience no net erosion or deposition and transports the bed-material sediment load delivered from upstream reaches. This balance indicates a stability of channel dimensions and is mathematically expressed as the familiar stream power proportionality (Lane 1955):

$$
Q S_{b} \propto Q_{s} D_{50}
$$

where $Q=$ discharge; $S_{b}=$ bed slope; $Q_{s}=$ bed-material discharge; and $D_{50}=$ median grain sizeof bed material, indicating that $50 \%$ of the bed material is finer.

Equation 1 indicates that if available stream power were augmented by an increase in the discharge or the gradient of the stream, there would be an excess amount of stream power relative to the discharge of bed-material sediment whose resistance is a measure of particle diameter. A similar response would be expected from a decrease in the erosional resistance of the channel boundary or a decrease in the size of bedmaterial sediment (assuming the bed is not cohesive). In contrast, a decrease in available stream power or an increase in the size or discharge of bed-material sediment would lead to aggradation on the channel bed.

The conceptual and semi-quantitative relation provided by Lane (1955) still provides only limited insight into the type and hierarchy of adjustment processes. Excess stream power may erode additional sediment from the channel boundary (depending on the resistance of the boundary), however, Equation 1 does not indicate where the erosion will occur and, therefore, how channel form might change. Determining the current size, shape and stream type of the channel will not address this question. Identifying in-stream sediment sources and dominant processes of adjustment and morphologic change in this case becomes a matter of determining the relative resistance of the bed and bank material to the applied forces imposed by the flow and/or by gravity. For a sand-bedded stream with cohesive banks, an initial adjustment might involve streambed incision because of low critical shear stresses, higher applied shear stresses on the bed than on the bank-toe, and more frequent exposure to hydraulic shear than adjacent streambanks. Conversely, if we assume that the streambed is highly resistant, composed of cohesive clays, bedrock, or large clasts such as cobbles or boulders, and that the bank-toe is composed of significantly weaker materials, we could expect bank erosion to be the initial adjustment.

Channel evolution models (CEMs) of Schumm et al. (1984) and Simon and Hupp (1986) use channel form, but use it to distinguish "stream types" as stages of channel evolution. These systems provide insights into active, dominant channel processes and can be used to interpret channel-adjustment trends over time and space. The schemes incorporate the concept of balancing stream power (or flow energy) and sediment supply, and have been found to be applicable in many diverse regions. The schemes have widespread applicability because they are based on the shifting balance or imbalance between driving and resisting forces (processes) and are not tied to specific ranges of channel shape. Use of CEMs further permits the user to determine whether channel instabilities are local or represent the adjustment of an entire fluvial system. Still, CEMs represent just another conceptual/empirical model and are not intended for engineering design or for quantifying channel response. They do, 
however, provide the user with a reconnaissance tool and knowledge of what processes are currently active and, therefore, what measurements and analyses are required to make quantitative predictions of channel response.

Rosgen (2001: p. II-19) provides at least eight examples of channel evolution that can be "described and quantified" by sequences of stream types (ie. C to G to F to Bc; or $\mathrm{C}$ to $\mathrm{G}$ to $\mathrm{F}$ to $\mathrm{D}$ ). The stream-type approach in fact does not quantify channel response, nor does it explain how and why these sequences of forms occur, or, how two $\mathrm{C}$ channels, once disturbed, can result in different stable forms (a Bc, a $\mathrm{C}$, or a D). Similarly, Rosgen (1996) shows different evolutionary sequences for a disturbed E4 channel (p. 6-8 to 6-9). These examples are the crux of our criticism in that using channel form to interpret channel response at the expense of understanding processes can lead to significant errors in prediction. Using Rosgen stream types, how would a practitioner determine the "correct" channel dimensions to design a restoration project? If we assume that these eight examples are from a single morpho-climatic setting (perhaps the montane west?), we can assume that differences in the evolutionary sequences are probably the result of differences in boundary resistance to applied hydraulic and geotechnical stresses. If these examples are from diverse regions then we can assume that the variations in sequences are the result of differences in both boundary resistance ANLapplied stresses. Without a quantifiable knowledge of specific hydraulic, sediment-transport and geotechnical forces, the various evolutionary sequences of stream types represent nothing more than a prediction that the shape of the channels will change with time.

All but one of the eight evolutionary scenarios shown in Rosgen (2001) mirrors the CEMs sequences of stages: incision, then widening, then filling. Why not then acknowledge that once fluvial networks are disturbed such that they contain excess energy relative to the imposed upstream sediment load, that a systematic series of

processes controlled by the imbalance between driving forces and the resistance of the boundary sediments takes place, and it is this imbalance that controls rates and magnitudes of adjustment, and ultimately stable geometries? Neither the Rosgen classification nor the CEM's, can determine within a reasonable degree of certainty the resulting sediment loads, stable-channel geometries, or period of adjustment. To accomplish these tasks, numerical, process-based modeling tools are much better suited (Shields et al., 2003). In the past, process-based modeling may have been limited by the availability of either computational resources, or numerical models. However, with the proliferation of personal computers, and the increased availability of free or low-cost numerical models, there is great potential to quantify river processes via numerical modeling (ie. Simon et al., 1999; Langendoen, 2000).

\section{Why Not Collect Data That Can Be Used To Analyze Channel Processes?}

"Natural channel design" methodology encourages the collection of field data, much of it centered on describing channel form at the bankfull stage. The debate over the meaning and value of "bankfull" discharge and "bankfull" channel dimensions has intensified in recent years with the popularity of the Rosgen classification and the 
renewed focus on stream restoration and channel design. The bankfull discharge has been ascribed various meanings and levels of importance over the past 50 years since Leopold and Maddock (1953) published their research on hydraulic geometry. Although Dunne and Leopold (1978) described the discharge at the bankfull stage as the most "effective" at forming and maintaining average channel dimensions, given the variation in the recurrence interval of the bankfull discharge (Williams, 1978), others suggest that a more meaningful measure would be one based on flow frequency (Miller and Ritter, 1996; Juracek and Fitzpatrick, 2003; Simon et al., 2004). Nevertheless, considerable resources are being expended by state and federal agencies as well as by academic institutions to determine bankfull channel dimensions and regional curves (based on channel and basin characteristics) to predict the bankfull discharge (eg. Harman et al., 1999; Odem et al., 1999; Castro and Jackson, 2001). Although data collection efforts are applauded, the overriding emphasis on determining bankfull dimensions at the expense of other data-collection programs that is troubling (ie. reductions in funding for USGS stream gages).

Our criticism of data-collection activities associated with the "natural channel design" methodology (aside from those previously discussed regarding sampling of channel materials) is not that the technique does not encourage data collection, but that the data required for stability evaluation, for example, does not provide all the information required to perform analyses of channel response and behavior but rather, to make only a qualitative evaluation of relative stability. If resources are available to collect field data along a given reach or stream, why not collect data that would permit deterministic analysis of bed and bank processes (Simon, 1995)? For example, instead of, or in addition to determining the bank-erosion-hazard index (Rosgen, 1996 p. 6-41) to determine relative bank stability, why not collect shear-strength (cohesion, friction angle and bulk unit weight) and bank-toe erodibility data and perform bankstability modeling to determine critical conditions for stability (e.g. Bank-Stability and Toe-Erosion Model, Simon et al. 1999). Using such deterministic approaches, a practitioner is more likely to design a successful stabilization or restoration project.

Finally, data collection must be conducted above and below the reach in question to place the reach in the proper spatial context. Field data collected under the "natural channel design" methodology represents a single snapshot in time and utilizes a plethora of dimensionless ratios to describe relative channel stability with insufficient consideration for the spatial and temporal distribution of processes that control channel response in disturbed stream systems. Restoring a given reach that is surrounded by other unstable reaches will more than likely, not be successful. Designing a bank-stabilization scheme in an actively degrading reach will similarly, have little chance of success. These examples point to the critical importance of temporal and spatial scales in fluvial geomorphology.

\section{Temporal and Spatial Scales}

Because streams are open systems, an alluvial channel adjusts to altered environmental conditions (Eq. 1). Scour and/or fill may occur over the course of a 
storm hydrograph but this does not necessarily indicate instability because the short time period of the event is not indicative of progressive change over a period of years. In fact, the important distinctions between the processes of scour and degradation, and fill and aggradation are issues of scale. Temporal aspects of channel behavior are masked in form-based approaches because they are based on a snapshot in time, provide no means of determining the magnitude, frequency or duration of processes, and neglect the history of the landscape system.

The previous example highlights the importance of time scales in interpretation and analysis of channel form. In a classic paper, Schumm and Lichty (1965) demonstrate how even the dependency of variables can change as a function of the time scale considered. Variables describing channel form are indeterminate over geologic time, dependent over medium time scales and independent over short time scales. Anthropogenic disturbances can cause channel adjustments of the type and scale represented by geologic time, but over compressed time periods of 50-100 years. This then becomes the temporal scale of investigation that is most critical to practitioners involved in stream restoration and channel design. It is also the scale that is most difficult to define by form-based criteria because channel forms are changing with time. Non-linear, asymptotic adjustment of variables such as width, depth gradient, shear stress, stream power, and roughness can occur rapidly in these cases (Bull, 1979; Hey, 1979; Williams and Wolman, 1984; Simon, 1992, 1994; Simon and Thorne, 1996). Because of this, it is critical for the practitioner to appreciate that the form (and possibly stream type) that they measure today may not be the same that they measure tomorrow or next year. The reason the forms are different (evolve) is because the reach is continually adjusting to the changing sediment supply from upstream and the imbalance between force and resistance which leads to a shift in dominant adjustment processes. This dynamic nature of channels was recognized long ago by Heraclitus (quoted by Kitto, 1951, p. 182): "You cannot step in the same river twice for the second time it is not the same river."

\section{Discussion and Summary}

Empirical approaches such as those inherent in "natural channel design" or CEMs do not provide cause and effect solutions or means of predicting stable channel dimensions and represent only one possible alternative to evaluating stream channels. CEMs are best applied at the reconnaissance level because they can provide a systemwide evaluation of the distribution of channel processes and inherently acknowledge that fluvial networks are open systems. The Rosgen classification is probably best applied as a communication tool to describe channel form. It is critical to understand though that a given channel form can be the result of many combinations of processes (equifinality) and, therefore, is not diagnostic of how or why a system is unstable or how to make it stable (Schumm, 1991). Physically-based, deterministic approaches on the other hand rely on quantifying the driving and resisting forces that control active processes and ultimate channel morphology, be they hydraulic, hydrologic or geotechnical. The physics of erosion, transport, and deposition are the same regardless of what hydro-physiographic province one is in or what the stream type 
may be, because of the uniformity of physical laws. Channel adjustment is driven by the imbalance between driving and resisting forces, sediment supply and sedimenttransporting capacity. Determining rates and magnitudes of adjustment, sedimenttransport rates and ultimate channel forms are a matter of defining those spatiallyand temporally-varying forces and variables.

Physically-based approaches that concentrate on processes do not require extraordinary data collection or analytic efforts. Our experience is that the field data required to analyze and predict channel response, including resistance of bed and bank material to erosion, can be collected at a site in one day. For all the emphasis placed on collection of field data and the effort and resources associated with data collection, it is surprising that the "natural channel design" methodology does not aim to quantify the very variables and processes that control channel processes and morphology. Practitioners should make use of the best available science and analytic approach that is appropriate to the scale and resources of the project.

While there are several reasons for limiting the use of classifications in restoration design, there are equally important reasons for maximizing the use of physicallybased analyses in restoration design. The foremost advantage of the process-based approach is that it is well established in the scientific and engineering literature. For decades, geomorphologists and hydraulic engineers have been quantifying river processes and developing models that have been tested and refined over time. Developing a design using this rich literature leverages off of a substantial scientific background, and thus provides a critical foundation from which to defend the design approach. Such literature and historical precedence is lacking for the classification approach. Practitioners concerned with professional liability and with the future of their professions would do well to provide design services based on peer-reviewed professional standards (e.g. Shields et al. 2003).

\section{References}

Ashmore, P., (1999). What would we do without Rosgen? Rational regime relations and natural channels. 2nd Intl. Conference on Natural Systems Design, Niagara Falls, Canada, published on CD-ROM.

Bull, W.B., (1979). Threshold of critical power in streams. Bull. Geological Society of America, 90: 453-464.

Church, M., and K. Rood, (1983). Catalogue of Alluvial Channel Regime Data. Department of Geography, University of British Columbia, Vancouver, 99pp.

Castro, J.M. and P.L. Jackson. (2001). Bankfull discharge recurrence intervals and regional hydraulic geometry relationships: patterns in the Pacific Northwest, USA. Journal of the American Water Resources Association 37(5):1249-1262.

Davis, W.M. (1909). Geographical essays, Ginn, Boston (republ.) 1954, Dover, New York).

Doyle, M.W., and Harbor, J.M., (2000). Evaluation of Rosgen's streambank erosion potential assessment in northeast Oklahoma. Journal of the American Water Resources Association, 36(5): 113-121.

Dunne, T. and Leopold, L.B., (1978). Water in Environmental Planning. W.H. Freeman and Company, San Francisco, 818 p. 
Elliott, J.G., Gellis, A.C., and Aby, S.B., (1999), Evolution of arroyos: Incised channels of the southwestern United States. p.153-186 In Incised Channels: Processes, Forms, Engineering, and Management. S. E. Darby and A. Simon eds., John Wiley \& Sons Inc., Chichester.

Gilbert, G.K. (1914). The transportation of debris by running water. U.S. Geological Survey Professional Paper 86.

Gregory K.J., and D.E. Walling (1973). Drainage Basin Form and Process: A Geomorphological Approach. Edward Arnold, London.

Harman, W.H., Jennings, G.D., Patterson, J.M., Clinton, D.R., Slate, L.O., Jessup, A.G., Everhart, J.R. and Smith, R.E., (1999). Bankfull hydraulic geometry relationships for North Carolina streams. In, D.S. Olsen and J.P. Potyondy (Editors.) Proc. Wildland Hydrology Symposium, AWRA, Bozeman, MT.

Hey, R.D., (1979). Dynamic process-response model of river channel development. Earth Surface Processes and Landforms, 4: 59-72.

Juracek, K.E. and F.A. Fitzpatrick, (2003). Limitations and implications of stream classification: Journal of the American Water Resources Association, 39(3): 659670.

Kitto, H.D.F., (1951). The Greeks, Penguin Books, New York.

Kondolf, G. M., (1995). Geomorphological stream channel classification in aquatic habitat restoration: uses and limitations. Aquatic Conservation: Marine and Freshwater Ecosystems 5: 1-15.

Kondolf, G.M., M.W. Smeltzer, and S. Railsback, (2001). Design and performance of a channel reconstruction project in a coastal California gravel-bed stream: Environmental Management, 28(6):761-776.

Kondolf, G.M., T.E. Lisle, and G.M. Wolman, (2003). Bed sediment measurement. p. 347395 in Tools in Fluvial Geomorphology. G.M. Kondolf and H. Piégay, eds., John Wiley \& Sons, Chichester, UK.

Knighton, D. (1998). Fluvial Forms and Processes. John Wiley and Sons, New York, 383 p.

Kuhnle R., and Simon, A., (2000). Evaluation of Sediment Transport Data for Clean Sediment TMDL's. National Sedimentation Laboratory Report 17, Oxford, Mississippi, $65 \mathrm{p}$.

Lane, E.W. (1955). Design of stable alluvial channels. Transactions, American Society of Civil Engineers 120(2776):1234-1260.

Langendoen, E. J. (2000). "CONCEPTS - CONservational Channel Evolution and Pollutant Transport System," National Sedimentation Laboratory Report 16, Oxford, MS.

Leopold, L.B. and Maddock Jr., T., (1953). The hydraulic geometry of stream channels and some phyisiographic implications. U.S. Geological Survey Professional Paper 252, $57 \mathrm{p}$.

Leopold, L.B., Wolman, M.G. and Miller, J.P., (1964). Fluvial Processes in Geomorphology. W.H. Freeman and Co., San Francisco, 522 p.

Malakoff, D., (2004). The River Doctor. Science 305: 937-939.

Miller, J. R. and J. B. Ritter, (1996). An examination of the Rosgen classification of natural rivers. Catena 27: 295-299.

Montana Department of Fish, Wildlife and Parks (MDFWP), (1998). Request for Proposal for the Renaturalization of Trout Creek.

Montgomery, D.R., and J.M. Buffington, (1997). Channel-reach morphology in mountain drainage basins. Geological Society of America Bulletin, 109: 596-611.

Morisawa, M. (1968). Streams: Their Dynamics and Morphology. McGraw-Hill, New York.

Odem, W.O., Moody, T., Knight, K. and Wirtanen, M., (1999). Stream channel morphology in New Mexico: Regional relationships. Northern Arizona University, Dept. Civil and Environmental Engineering, Flagstaff, AZ. 
Richards, K. (1982). Rivers:Form and Process in Alluvial Channels, Methuen, London, 358 Rosgen, D.L., (1994). A classification of natural rivers. Catena 22: 169-199.

Rosgen, D.L., (1996). Applied River Morphology. Wildland Hydrology, Pagosa Springs, CO.

Rosgen, D.L., (2001). A stream channel stability methodology. Proc., Seventh Federal Interagency Sedimentation Conference, Reno, NV. p. II-18 to II-26, on CD.

Sack, D., 1992. New wine in old wine bottles: the historiography of a paradigm change. Geomorphology, 5: 251-263.

Schumm, S.A., (1960). The shape of alluvial channels in relation to sediment type. U.S. Geological Survey Professional Paper 352-B, 30 p.

Schumm, S.A. (1977). The Fluvial System. John Wiley \& Sons, New York, 338 pp.

Schumm, S.A., (1991). To Interpret the Earth: Ten Ways To Be Wrong. Cambridge University Press, Cambridge, England.

Schumm, S.A., M.D. Harvey and C.C. Watson (1984). Incised Channels: Morphology, Dynamics and Control. Water Resources Publications, Littleton, Colorado, 200 pp.

Schumm, A., and Lichty, R.W., (1965). Time, space and causality in geomorphology. American Journal of Science, 263, 110-119.

Shields, F.D., Jr., Copeland, R.R., Klingeman, P.C., Doyle, M.W., and Simon, A., (2003). Design for stream restoration. Journal of Hydraulic Engineering, 129(3): 575-584.

Simon, A., (1989). A model of channel response in disturbed alluvial channels. Earth Surface Processes and Landforms 14: 11-26.

Simon, A. (1992). Energy, time, and channel evolution in catastrophically disturbed fluvial systems. In Geomorphic Systems: Geomorphology. J.D. Phillips and W.H. Renwick eds. 5: 345-372.

Simon, A. (1994). Gradation processes and channel evolution in modified West Tennessee streams: Process, response, and form. U.S. Geological Survey Professional Paper 1470, $84 \mathrm{pp}$.

Simon, A., (1995). Adjustment and recovery of unstable alluvial channels: Identification and approaches for engineering management. Earth Surface Processes and Landforms, 20: 611-628.

Simon, A., Curini, A., Darby, S.E., and Langendoen, E., (1999). Streambank mechanics and the role of bank and near-bank processes in incised channels. 123-152 in Incised Channels: Processes, Forms, Engineering, and Management. S. E. Darby and A. Simon eds., John Wiley \& Sons Inc., Chichester.

Simon, A., Dickerson, W., and Heins, A., (2004). Suspended-sediment transport rates at the 1.5-year recurrence interval for ecoregions of the United States: Transport conditions at the bankfull and effective discharge? Geomorphology, 58: 234-262.

Simon, A. and Hupp, C. R., (1986). Channel evolution in modified Tennessee channels, Proceedings of the Fourth Interagency Sedimentation Conference, March 1986, Las Vegas, NV, 2, 5-71 to 5-82.

Simon A., and Thorne, C.R., (1996). Channel adjustment of an unstable coarse-grained stream: Opposing trends of boundary and critical shear stress, and the applicability of extremal hypotheses. Earth Surface Processes and Landforms, 21: 155-180.

Williams, G.P., (1978). Bankfull discharge of rivers. Water Resources Research 14:11411154.

Williams, G. P. and M.G. Wolman (1984). Downstream effects of dams on alluvial rivers. U. S. Geological Survey Professional Paper 1286, 83 pp. 